\title{
ANALYSIS OF ADDITIONAL CFT SUPPORT AT Z=0 FOR THE SILICON HALF TROUGH
}

\author{
D-ZERO ENGINEERING NOTE \# 3823.112 EN-523
}

Author: Herman Cease, PPD/ETT/D-Zero Mech.

Ang Lee, PPD/ETT/MSD

March 20, 2000

Approved By:

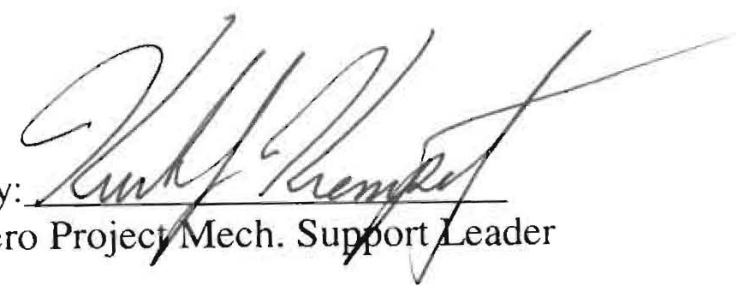




\section{Summary:}

The D-Zero silicon trough is segmented into two half troughs. Loading to the Central Fiber Tracker Barrel 1 is at both ends and near $Z=0$. The loading near $Z=0$ is thought to be $4 \mathrm{lbs}$ at 4 points. The point locations are at $+/-45$ degrees for each half trough on each side of $Z=0$. An additional support at $Z=0$ is required to prevent beam sag and out of round distortions to the CFT Barrel 1. An additional joining washer will be attached between barrels 1 and 2 at $Z=0$. Also a support ring will be attached to the inner diameter of barrel 1 to further help in out of round distortions. Details of the washer and loading are modeled using ANSYS.

\section{Analysis:}

The inner support ring is a double I-beam structure. The flanges are 0.040 inch thick and the web is 0.020 inch thick. The lower and upper flanges are 1.56 inches wide. The webs are located at $+/-0.39$ inch in $Z$. The total radial thickness of the ring is 0.304 inch. The ring is continuous around the circumference.

The support ring that attaches the outer diameter of barrel 1 to the inner diameter of barrel 2 is a single I-beam structure. The flanges and web are 0.020 inch thick. The web location is at $\mathrm{Z}=0$. The flange width is 0.78 inch. The ring is continuous around the circumference.

ANSYS input parameters are:

Loading: $8 \mathrm{lbs}$ per point (a safety factor of 2 on the estimated loading) near $\mathrm{Z}=0$

1 point at +45 degrees and $Z=-0.39$ inch

1 point at -45 degrees and $Z=0.39$ inch

1 point at +45 degrees and $Z=0.39$ inch

1 point at -45 degrees and $Z=-0.39$ inch

loading direction: vertical on the inner diameter of CFT barrel 1 .

A total load of $125 \mathrm{lbs}$ distributed over 4 points was also added to the CFT barrel 1 at the end ring ( $\mathrm{Z}=33$ inches) for beam pipe and silicon trough loading. The one point in the quadrant modeled was at 45 degrees from the bottom and located over the CFT barrel 1 end ring. This load is thought to be a circumferential line load but was modeled as a point load.

Stiffening ring material: carbon fiber with a composite modulus of $12 \mathrm{mpsi}$

All 8 barrels were modeled. The barrel composite consisted of an inner layer of carbon fiber ( 0.010 inch $105 \mathrm{Mpsi}$ fiber for barrels 3 and 4, the remaining barrels are 0.015 inch with $55 \mathrm{Mpsi}$ fiber), a layer of Rohacell ( $0.250 \mathrm{inch})$, another layer of carbon fiber, a layer of glue (0.020 inch), and a layer of ribbons (0.105 inch).

Symmetry planes were used, only a quarter of the full tracker was modeled. 


\section{ANSYS results,}

Plots are given showing distortions and stresses for barrels 1 and 2 only.

Plot 1 is distortions in the vertical direction with units of inch. The radial out of round distortion is 0.0005 inch. The beam sag distortion is 0.0007 inch.

Plot 2 shows the Von Mises Stresses in the ribbon material on barrels 1 and 2 . The highest magnitude is 27 psi near the location of the loading.

Plot 3 is a general picture of the added support structure near at $Z=0$. The entire structure is not shown due to the symmetry planes.

\section{Conclusions:}

The addition of a support structure to CFT barrels 1 and 2 is required to prevent distortions due to the loading of the silicon half troughs at $\mathrm{Z}=0$. A support ring is attached to the inner diameter of barrel 1 to distribute the point loads from the silicon supports. An additional ring is used to attach barrels 1 and 2. The system was modeled using ANYSIS. Results showed an out of round distortion of 0.0005 inches and a beam sag distortion of 0.0007 inches. The stress magnitude in the barrel 1 ribbons was found to be 27 psi. The distortions and stresses as modeled are at an acceptable level. 


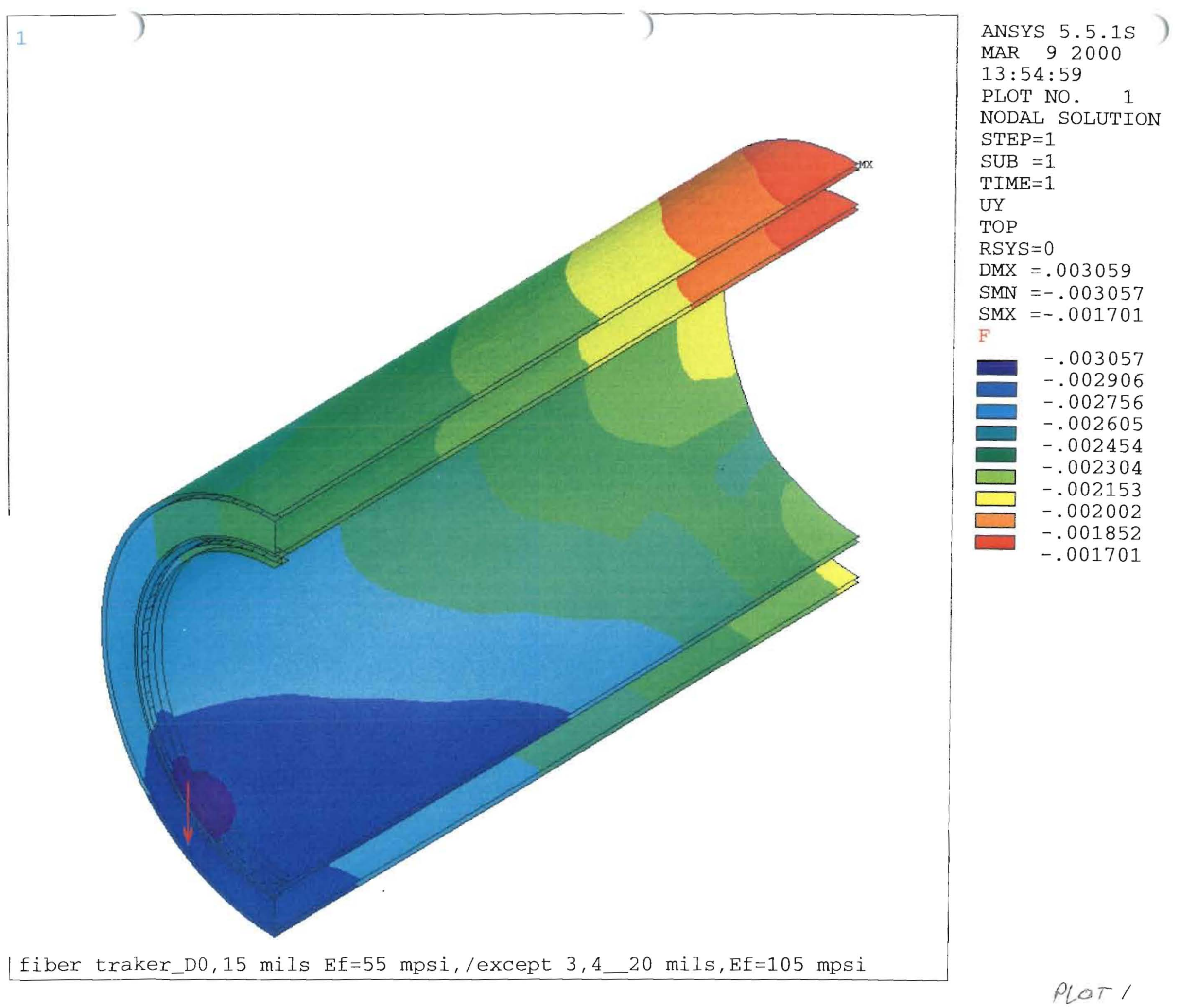


PLOT NO. 4 NODAL SOLUTION STEP $=1$

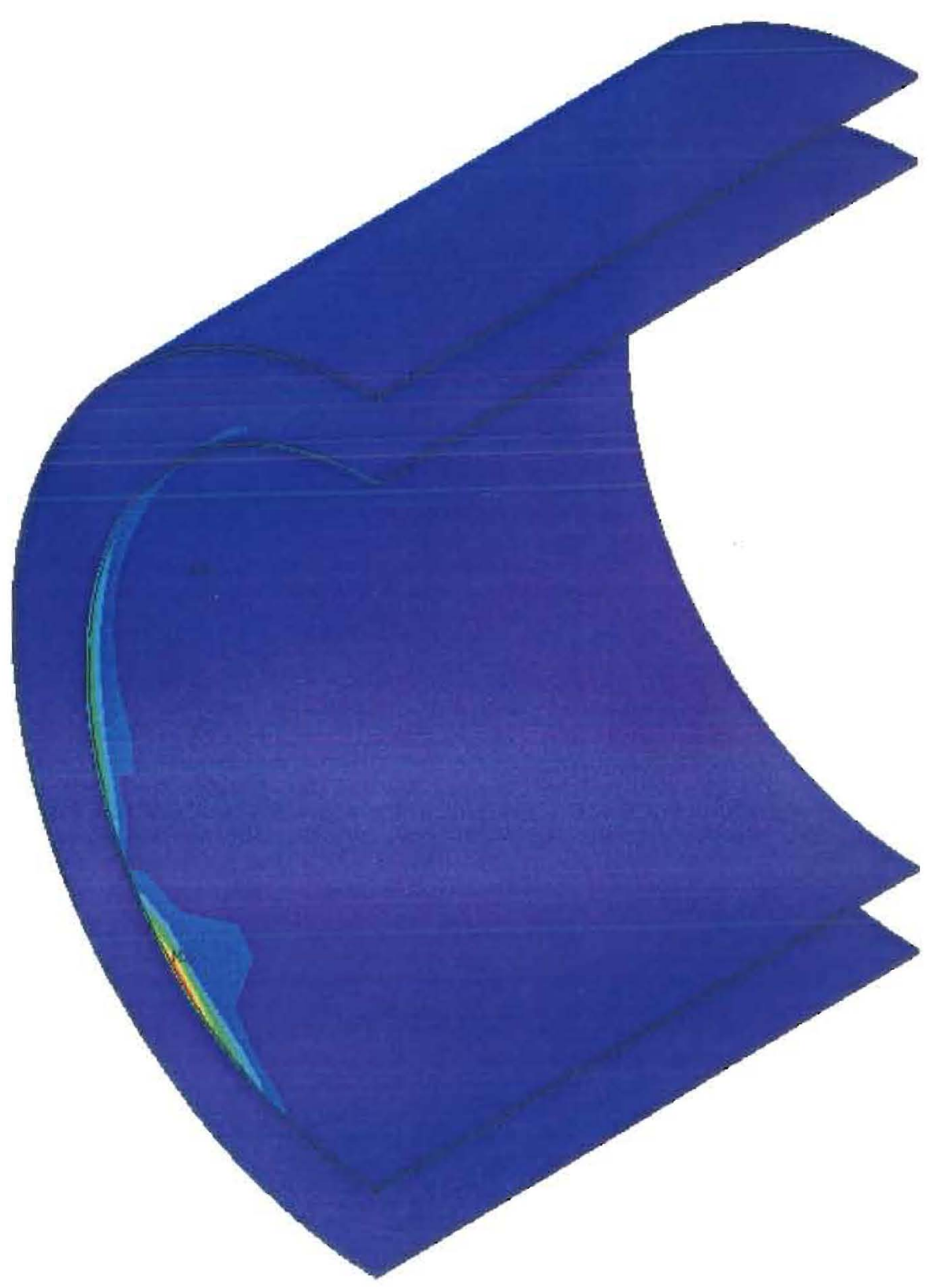

SUB $=1$

TIME $=1$

SINT

TOP

$\mathrm{DMX}=.002942$

SMN $=.350701$

SMX $=27.461$

.350701

3.363

6.375

6.387
$-\quad 9.387$

12.4

$\square \quad 15.412$

18.424

21.436

24.449

27.461

fiber traker_D0,15 mils Ef=55 mpsi,/except 3,4_20 mils, Ef=105 mpsi 


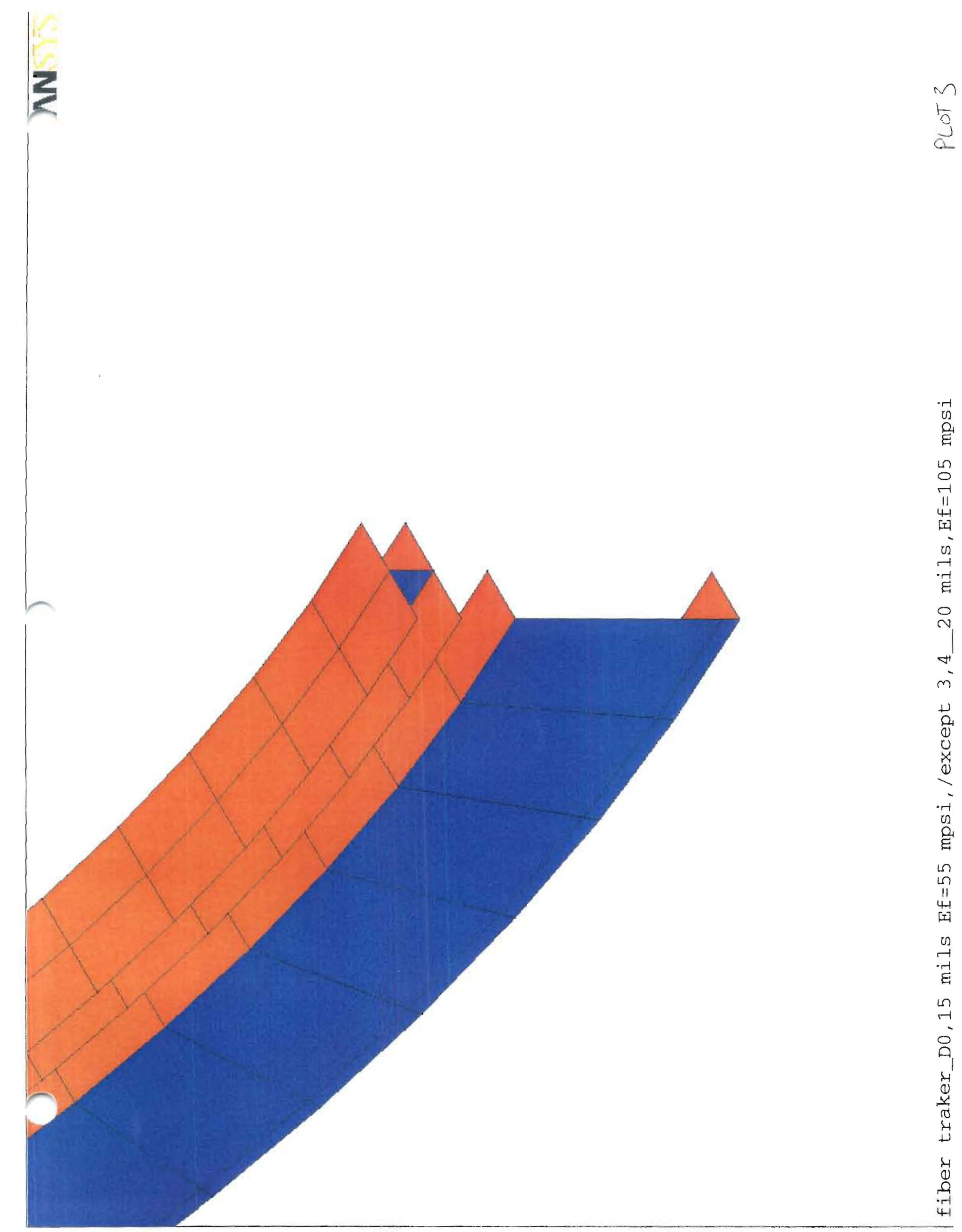

OI 